\title{
UM FORROBODÓ DA RAÇA E DA CULTURA
}

\section{Antonio Herculano Lopes}

A noite de 11 de junho de 1912 testemunhou um fenômeno de dimensão ainda não devidamente reconhecida em seu impacto e significação para a cultura urbana carioca e para o desenvolvimento do conceito de identidade nacional que se tornaria prevalecente nas décadas seguintes. Era a estréia de Forrobodó, burleta escrita por dois jovens jornalistas da alta classe média do Rio de Janeiro - Luís Peixoto e Carlos Bittencourt com música da celebrada Chiquinha Gonzaga, numa produção da Companhia de Operetas, Burletas e Revistas do Teatro São José.

Naquela tarde, o teatro estava em atividade febril como costuma acontecer nas estréias, mas o ambiente era de incertezas. O empresário Pascoal Segreto, que estava se tornando o todo poderoso rei da praça Tiradentes, e tinha o faro

Artigo recebido em janeiro/2005

Aprovado em julho/2006 do sucesso, não confiava na peça. Sua falta de entusiasmo e apoio financeiro já havia causado umas tantas postergações da estréia. Afinal, aqueles neófitos tinham tido uma idéia assaz esdrúxula e audaciosa: escrever uma peça baseada na comunidade negra carioca, com seus característicos linguajar, música, dança, personagens e preocupações cotidianas.

Luís Peixoto deixou o teatro mais cedo, acabrunhado, temendo o insucesso. Os técnicos e cenógrafos iam e vinham na costumeira excitação de última hora, mas também não escondiam seus sentimentos. O ator principal, Alfredo Silva, tratava de tirar de Carlos Bittencourt suas últimas ilusões. A julgar pelo relato que nos chegou através de Marisa Lira (1978), a única a confiar plenamente no êxito era a experiente Chiquinha. E ela estava certa. Forrobodó tornou-se um dos maiores sucessos do teatro brasileiro de todos os tempos, sendo apresentado mais de 1.500 vezes consecutivas, estatística que, se não é muito confiável, é 
suficientemente eloqüente para dar a dimensão do fenômeno, que aparece ainda como mais extraordinária se pensarmos nas dimensões da população e dos freqüentadores de teatro de então.

A estréia causou imediata comoção e a peça passou a merecer uma atenção da imprensa nada habitual para este gênero de espetáculo. Segundo O Pais (17 e 26/6/1912 e 12/7/1912), jornal em que Carlos Bittencourt trabalhava, nas primeiras semanas o público brigava histericamente por ingressos na bilheteria e a aglomeração diante do teatro às vezes chegava a obstruir a passagem dos bondes, forçando a polícia a intervir. As 22 sessões semanais de Forrobodó lotavam com meses de antecedência, algo inédito na história das diversões públicas da cidade. Tamanho sucesso sugere perguntas como as que Gramsci (1985, p. 120) formulou ao estudar a literatura popular italiana: Por que esse produto se tornou tão consumido? A que necessidades satisfazia? No presente ensaio, examinarei vários aspectos relacionados à produção de Forrobodó - texto, música, cenário, figurinos, atuação -, enfrentando os limites da escassa informação que sobreviveu para buscar algumas possíveis respostas.

Lancemos primeiro um olhar nos autores. A dupla de escritores, como já disse, estava ainda engatinhando na indústria do entretenimento, em que teriam longa e bem-sucedida carreira. Com seus vinte e poucos anos cada um, já haviam colaborado, com boa resposta de público, em alguns esquetes cômicos que seguiam a fórmula de tratar de maneira bem humorada a cultura carioca dos bairros populares e subúrbios. Ambos já estavam razoavelmente estabelecidos como profissionais de imprensa - Peixoto como ilustrador e chargista desde os 14 anos e Bittencourt como repórter policial conhecido pelas reportagens em prosa rimada. Mas se alguém tinha reconhecimento público suficiente para atrair fãs ao teatro era a compositora e maestrina (como era usualmente chamada) Chiquinha Gonzaga. E parece não haver dúvida de que sua partitura foi em grande parte responsável pelo sucesso de Forrobodó. Os jornais referiram-se à sua música como "admirável" (Correio da Manhã, 12/6/1912), "buliçosa" (A Noite, 12/6/1912), "leve e saltitante" (Correio da Noite, 12/6/1912), "espontânea, brejeira e tem uns maxixes de levantar um morto da campa" (Gazeta da Tarde, 12/6/1912). Na
Folha do Dia, José Caetano (provavelmente um pseudônimo) simplesmente declarou:

Para [a burleta] escreveu a inspirada maestrina Francisca Gonzaga uma das suas melhores partituras, caracteristicamente nacional, casando-se admiravelmente com o assunto e dando-lhe extraordinário brilho.

Só a música, pode-se dizer sem medo de cair em erro ou exagero, garante o sucesso da peça. Tem uns versos encantadores (Folha do Dia, 12/6/1912).

Mais do que a opinião crítica, o sucesso popular da partitura de Chiquinha comprova a importância da compositora na transformação de Forrobodó no fenômeno que se tornou. A canção Não se impressione, em particular, logo passou a ser cantada em toda parte. Mas arrisco dizer que a excelência do trabalho de Chiquinha não explica a sensação de novidade que envolveu o espetáculo. Não tenho a competência técnica para analisar sua partitura e qualidade musical, o que seria importante para uma avaliação mais exata de seu impacto naquele momento, mas a carreira da compositora não ficou marcada pelo que ela fez especificamente neste espetáculo. Desde que fez suas primeiras tentativas de composição para o teatro, em princípios dos anos de 1880, a ligação de Chiquinha com a cena só fez crescer e chegou a seu ápice na época da estréia de Forrobodó. No Teatro São José, ela trabalhou intensamente, já havia criado a partitura de ao menos dois espetáculos antes deste e logo em seguida começaria a trabalhar no próximo.

A criação no teatro musical ligeiro do período obedecia a um ritmo de linha de montagem, com os espetáculos se revezando rapidamente em cartaz. Chiquinha ainda compunha para outras companhias, como a de Álvaro Colás, para quem musicou Pudesse esta paixão..., estreada no Teatro Apolo no final de 1912 (O Imparcial, 2/1/1913). As apreciações críticas com freqüência referiam-se à sua música como "característica" (ver citação de José Caetano, anteriormente), o que era um código bastante preciso para aludir ao uso de ritmos populares afro-brasileiros, em especial o tango brasileiro ou maxixe.

Mas se o gênero ainda era considerado escandaloso, nem por isso era novidade, pois a dança e o ritmo do maxixe já estavam presentes 
nos palcos cariocas pelo menos desde que o ator Vasques, em 1883, criou o personagem do caradura, um malandro maxixeiro (Tinhorão, 1978, p. 60). Artur Azevedo, com sua autoridade, ajudou a consagrar o gênero ao usar o tango As laranjas da Sabina na sua revista $A$ República, de 1890 . A própria Chiquinha teve seus maxixes no palco ao menos desde 1897, quando o famoso O gaúcho, que se tornou conhecido como O corta jaca, fez sua estréia na revista Zizinha maxixe, de Machado Careca.

No momento da estréia de Forrobodó, o maxixe, como dança e como gênero musical, já se tornara indispensável para o teatro musical ligeiro carioca, com crescente aceitação ao longo de vinte anos. É verdade que ainda provocava enormes reações e resistências, sobretudo entre as classes mais altas, mas a fortaleza do conservadorismo começava a apresentar fraturas.

Desde o começo do século XX, la matchiche viajava pela Europa. Na segunda década, chegava aos Estados Unidos através do casal de bailarinos Vernon e Irene Castle. Um processo cultural semelhante, aliás, vinha ocorrendo nesse país, com novas formas de dançar e representar que se associavam a um processo de mudança de valores morais, provocando, com efeito, reação do público.

Naqueles tempos [1905 a 1913], a América estava se desnudando de velhas coibições, até o mais íntimo das roupas de baixo de lã. As saias subiam acompanhadas por assobios [...]. A valsa e o twostep eram gradualmente retirados das pistas de dança pelo compasso sincopado do ragtime em danças sensuais como o turkey trot (trote de peru), o grizzly bear (urso pardo), o bunny hug (abraço de coelho) e o maxixe (Green e Laurie, 1985 , p. 6 , trad. minha).

Entre 1909 e 1910, a dupla de maxixeiros Duque e Maria Lino dançou com enorme sucesso em Paris, Londres e Berlim. Duque abriu uma academia para ensinar o "tango brasileiro" aos parisienses. Com outra parceira, a francesa Gaby, dançou para George $\mathrm{V}$ da Inglaterra, para Henri Poincaré, presidente da França, e, em 1913, para o papa Pio $\mathrm{X}$, que queria conferir se a dança era aceitável aos cristãos. Claro que o tango de Duque era muito mais estilizado e menos ousado do que o maxixe dançado pelas classes baixas cariocas em seus bailes, ou mesmo pelos artistas do teatro musical. Mas para a intelligentsia brasileira em sua busca de uma "cultura nacional", era difícil lidar com a idéia de que aquelas músicas e danças tão vulgares, tão associadas com a população negra, pudessem representar o Brasil com sucesso no exterior.

No entanto, sinais de que a resistência dos intelectuais não era tão homogênea podiam ser percebidos, e o número dos que aceitavam o maxixe como "caracteristicamente nacional" aumentava. Não é de se espantar que o sucesso na Europa tenha sido crucial para essa aceitação. Os atores, que contavam entre os principais aliados da absorção da cultura das ruas pelos palcos, ganhavam um argumento de peso na defesa de sua arte. Asdrúbal Miranda, que fazia parte do elenco de Forrobodó, declarou numa entrevista:

O maxixe é uma dansa exclusivamente nossa, como são o café e o sabiá. O governo constantemente gasta rios de dinheiro para introduzir na Europa [ilegível]. Tem conseguido alguma coisa mas não tanto quanto os que espontaneamente no Velho Mundo, ao som do Vem cá mulata, movimentam as pernas e o corpo no remelexo característico da nossa dança (O Imparcial, 2/1/1913).

Num artigo de 1914, o escritor e homem de teatro Álvaro Moreira observou que na França o maxixe já vinha chamando a atenção de poetas e dramaturgos (Fon-Fon, 4/4/1914). Mas isso não era suficiente para ganhar a aceitação dos círculos conservadores. Em 1917, Coelho Neto, então diretor da Escola Dramática, terminava uma palestra sobre dança dizendo que "não temos uma dança própria. E isso porque não temos ainda uma raça definida" (O Imparcial, 1/7/1917). Nesta afirmação fica evidente o grau de sobreposição entre as noções de raça e de nacionalidade: franceses e outros povos europeus têm uma nação por constituírem uma raça definida, homogênea.

Tanto as elites políticas como as religiosas do país compartilhavam a dificuldade em se relacionar com a heterogeneidade social e cultural e, em especial, com os traços que pudessem ser associados a uma origem africana. O que, aos olhos europeus, poderia ser visto como um exotismo merecedor de atenção, aqui aparecia como a marca de 
nossa vergonha. Assim, enquanto o próprio papa reagia favoravelmente à apresentação de Duque, o cardeal Arcoverde proibia a dança para os católicos brasileiros. O famoso episódio da reação irada de Rui Barbosa ao fato de Nair de Teffé tocar o Corta jaca no palácio do Catete ocorreu significativamente no mesmo ano da estréia de Forrobodó.

A controvérsia, portanto, corria solta, mas o maxixe e os ritmos "característicos" usados por Chiquinha na peça não eram mais nenhuma novidade. Ao contrário, poder-se-ia dizer mesmo que os cariocas sofriam de uma superexposição à polêmica. O que era novo, ao menos para as platéias de classe média e alta, freqüentadoras dos principais palcos da cidade, era o fato de o espetáculo ser todo centrado em torno do próprio ambiente sociocultural de onde emanara o maxixe. Esta fora a grande contribuição de Luís Peixoto e Carlos Bittencourt.

A maior parte das apreciações críticas, além de elogiar o trabalho da maestrina, realçava o grau de verdade com que os autores conseguiram reproduzir a atmosfera, os costumes e a forma de falar das populações dos bairros pobres do Rio de Janeiro - ou, nas palavras de um crítico, "os hábitos do povo da lira" (Imprensa, 12/6/1912). A seguir alguns dos seus comentários:

Escrita com muita verve, sem excesso de pimenta [...], [Forrobodó] constitui um estudo muito bem feito da vida nos nossos arrabaldes modestos. [...] Os autores tiveram felicidade na observação dos tipos (Correio da Manhã, 12/6/1912).

Os citados autores [...] fizeram a peça com a mais fiel observação de um "baile-quermesse" e num clube da Cidade Nova, e com a mais flagrante verdade, copiando fielmente tipos e acontecimentos, tiveram o melhor resultado (Imprensa, 12/6/1912).

Os autores [...] procuraram exibir os tipos, os costumes, as usanças e as peripécias de um forrobodó de massadas, em um clube recreativo da Cidade Nova. E conseguiram-no com graça e observação flagrante, trazendo o público em constantes gargalhadas na successão das cenas (Jornal do Brasil, 13/6/1912).

A expressão "forrobodó de massadas" merece um comentário. Raul Pederneiras publicou um glossário de gírias cariocas em 1920, em que registra "massadas" como "pretextos, negaças, subterfúgios" (p. 33). Em vários textos de revistas da época, no entanto, o termo é usado com conotação positiva, significando "algo nosso, com a nossa malícia”, o que também parece ser o caso aqui. A associação com os movimentos da capoeira não é difícil de ser feita: o corpo que ameaça ir para um lado e vai para o outro, sempre ocultando de onde sai o golpe, sempre iludindo o adversário. Essa manha ou jogo de refugos reaparece em diversas expressões de gíria como uma característica da cultura popular afro-carioca.

A despeito de todas as boas críticas, do elogio unânime que a imprensa fez a Forrobodó, há que se tomar cuidado na análise de seu significado. Vários elementos externos influenciavam as boas e más críticas de teatro. É notável como os termos usados nas diversas críticas mencionadas se assemelham. Não seria de se espantar se elas tivessem sido escritas com base num material distribuído pela própria produção da peça. A crítica de teatro especializada era, na verdade, ainda inexistente e, exceto em casos como o de Artur Azevedo, que atuava como homem de teatro e jornalista, os articulistas não estavam em melhores condições de expressar um julgamento do que o leitor médio. É perfeitamente plausível que um produtor influente como Pascoal Segreto procurasse obter boas críticas para seus espetáculos e que profissionais da imprensa, como os autores de Forrobodó, contassem com a boa vontade dos jornais.

Por outro lado, as idiossincrasias de um dono de jornal poderiam conduzir a uma crítica tanto positiva como negativa. Entre os próprios jornalistas, havia os que simpatizavam com o teatro musical ligeiro e se dispunham a promovê-lo. Elogios enfáticos a qualquer peça nacional eram mesmo comuns à época. E havia os que sistematicamente o denegriam, clamando por um teatro "sério" que um dia redimisse os palcos brasileiros.

Com tais precauções em mente, voltemos às críticas já mencionadas, pois ainda será possível tirar-lhes algum proveito. Os comentários em geral concordaram em que a observação dos autores fora fiel ao seu objeto: um autêntico forrobodó de massadas. Mas se tais críticos/comentaristas não estavam bem preparados para exercer a crítica teatral, tinham ainda menos critério para falar da cul- 
tura dos bairros pobres e predominantemente negros do Rio de Janeiro. O que Bittencourt e Peixoto escreveram não estava muito distante da visão estereotipada dos negros compartilhada pela alta classe média carioca, com a diferença de terem os autores um real interesse pela cultura popular. A informação que podemos reter, portanto, é que as imagens criadas por Forrobodó correspondiam ao que jornalistas brancos de classe média imaginavam ser um baile popular de populações negras da Cidade Nova, suas formas de comportamento e seu jeito de falar.

Havia da parte dos autores uma clara intenção de usar essas formas de se comportar e de falar, características de determinado grupo social, para transformá-las em características da cidade, o que é revelado no subtítulo da peça: "uma burleta de costumes cariocas". E, assim, os comentaristas completam o movimento de generalização da cidade para o país.

Forrobodó é, para quem percebe da gíria nacional, um forrobodó completo; uma encrenca na Cidade Nova, após afinado baile, que se realiza á moda dos bailes daquela zona (A Noite, 12/6/1912).

A linguagem transforma-se em nacional da mesma forma que a música de Chiquinha é chamada de "caracteristicamente nacional", isto é, o nacional centrado no povo, que nos distinguia das demais culturas (européias) com que as elites se identificavam. Na sua busca do "nacional", uma parte da intelligentsia começava a olhar para um sujeito muito mais próximo do que o índio idealizado do Romantismo ou o caipira caricatural. Uma população urbana pobre, majoritariamente negra ou mestiça, que vivia ao seu lado ou mesmo dentro de suas próprias casas como empregados domésticos, começava a se oferecer a esses intelectuais como a chave para a especificidade brasileira.

No mundo da música, o diálogo criativo entre uma tradição erudita européia e uma popular de forte ascendência africana já vinha de longe. A contaminação da linguagem literária por aquela presente nas ruas tinha história bem mais recente, e talvez possamos identificá-la mais fortemente em autores naturalistas como Aluísio de Azevedo. No teatro oitocentista, França Jr. fazia uso ocasional da gíria. Os musicais ligeiros passaram a incorpo- rar cada vez mais termos do vulgo, mas foi entre atores de extração popular, como Vasques ou Xisto Bahia, em pequenos atos cômicos que se inseriam em espetáculos mais amplos, que essa circulação passou a ser maior. No começo do século XX, a absorção da linguagem das ruas pelo palco passou a ser um traço das revistas.

A Luís Peixoto e Carlos Bittencourt atribuíase o uso da "gíria capadócia" em Forrobodó. Eis aqui mais um termo ligado à idéia de subterfúgio e marcado pela ambigüidade. "Capadócio", como várias palavras ligadas à cultura afro-carioca, variava entre uma conotação negativa e outra positiva. Nos dicionários, e portanto na linguagem oficial, aparece como sinônimo de fanfarrão ou canalha. Naquela virada de século, era termo freqüentemente associado ao capoeira e, por extensão, com indivíduos de classe baixa, em especial os negros, como na expressão "gíria capadócia". Também mantém proximidade com "povo da lira", embora este aluda mais a uma boêmia ruidosa e festiva. Em todo caso, esses significados convergem numa idéia de desordem e, no limite, de arruaça. A linha da percepção positiva ou negativa desses conteúdos era muito tênue, e sobre ela caminhavam os intelectuais boêmios, em grande parte jornalistas, que se fascinavam pela cultura popular da cidade. A palavra "capadócio" acabou por se tornar obsoleta e foi substituída por "malandro", que herdou muito de sua duplicidade.

Peixoto e Bittencourt não foram os primeiros a usar a gíria capadócia no palco. O mérito, ou a pecha, de acordo com o ponto de vista, coube ou era atribuído a João Foca (pseudônimo de Batista Coelho), em sua opereta Não venhas, de 1904, que, aliás, também contava com maxixes de Chiquinha Gonzaga. Delso Renault (1980, p. 132) menciona que a insolência de Foca teve enorme repercussão naquele momento. Anos depois, em 1917, um crítico lamentava a hegemonia do "gênero forrobodó" nos palcos, atribuindo a Não venhas o pecado de ter aberto as portas do teatro brasileiro para a gíria (Comédia, 3/2/1917).

Forrobodó, portanto, não foi inovador nem na música nem na língua. A novidade estava na escala em que a peça procurava recriar o mundo existente por trás dessas linguagens. Esse mundo era percebido ao mesmo tempo como próximo e distante, o que pode ser atestado nas palavras de 
José Caetano, o mesmo crítico que chamou a música de Chiquinha Gonzaga de "caracteristicamente nacional":

[A peça] é um estudo consciencioso, hábil, cheio de graça e de observação dos bailes realizados em certa parte da cidade, e que toma determinado pessoal que fala diferente de nós e cujos usos e costumes, pitorescos, sem dúvida, transportados para a cena, não podiam deixar de dar, como deram, os mais seguros efeitos de curiosidade (Folha do Dia, 12/6/1912).

A forma como as populações negras dos bairros pobres do Rio de Janeiro falavam era tão exótica para um carioca das classes média e alta quanto para um estrangeiro que dominasse o idioma culto, digamos, um português. Forrobodó é cheia de expressões que requeriam da platéia certa intimidade com a gíria afro-carioca - como "dar a lata" (esnobar, ignorar) ou "desinfeta o beco" (saia, vá embora). Essa alteridade na linguagem era paradoxalmente usada como uma marca coletiva da cidade ou mesmo do país.

Tal foi o movimento criado por Peixoto e Bittencourt na peça: eles não estavam fazendo uma reprodução exata da realidade e provavelmente nunca tiveram essa intenção; mas por meio de uma apropriação e transformação artística do real, com o objetivo principal de divertir, estavam oferecendo imagens e símbolos identitários para uma população que não se reconhecia nos projetos identitários prevalecentes entre as elites. E para produzir diversão, a caricatura e o estereótipo eram armas poderosas.

Para conseguir o efeito "característico" da linguagem, os autores utilizaram-se de três mecanismos principais: o uso intenso de gíria; erros gramaticais comuns em meios de baixa escolaridade (como em concordâncias verbais e de número ou em formas de pronunciar palavras); e o uso de construções rebuscadas e afetadas, incluindo o uso impróprio de expressões eruditas e em língua estrangeira, principalmente o francês. Não houve, no entanto, maior preocupação com a coerência. O personagem do Guarda, por exemplo (um guarda noturno, de quarteirão), às vezes fala com correção surpreendente, às vezes, com todos os vícios e marcas de uma fala rústica, quase dialetal.
A intenção de fazer graça pelo exagero aparece de forma clara no personagem Escandanhas o secretário da Sociedade Flor do Castigo do Corpo da Cidade Nova, clube em que se dá o forrobodó. Ele é considerado muito inteligente pelo grupo e usa uma linguagem extremamente empolada (e incorreta) que resulta num xarabiá sem sentido. Barradas, o presidente do clube, é um pequeno comerciante português, com sua maneira própria de falar, também baseada em estereótipos, no caso dos imigrantes pobres portugueses, com seu sotaque e erros gramaticais. Madame Petit-Pois, o personagem da prostituta que se apresenta como francesa (o que certamente é falso), mistura um mau francês com português, basicamente adaptando a fonética de uma língua ao vocabulário e construções da outra, como no dueto em que canta com o Guarda: "Viens comigue, maxixê".

O uso humorístico de todas essas diferentes formas de falar nos meios populares tampouco foi uma novidade introduzida por Peixoto e Bittencourt. O falar estropiado dos negros era amplamente explorado e, para ficar apenas num antecedente mais próximo, João do Rio e J. Brito o haviam utilizado num monólogo, Chic-chic, para fazer troça do único deputado negro na Câmara, Monteiro Lopes. No jornal O País, uma coluna chamada "O povo da lira" era especializada nesse tipo de sátira de cunho racista, o que aliás era comum em charges e anedotas circuladas por quase toda a imprensa. Era um meio de estabelecer claros limites de classe (sobrepostas à noção de raça), com uma mensagem subentendida: "Os brancos somos a parte melhor da sociedade e da cultura brasileira, que deverá prevalecer para que o país se torne civilizado".

Aqui se encontra talvez a mais importante contribuição de Forrobodó: a peça marca um ponto de transição entre a sátira que rebaixa e a que eleva a contribuição de origem africana para a cultura da cidade e do país; entre o desprezo e a celebração. O processo de absorção e de representação deste Outro de uma sociedade que se queria européia já vinha ocorrendo há tempos, aos trancos e barrancos. Mas a maior parte de tais representações carregava no tom depreciativo. Forrobodó, com todas as suas ambivalências e estereótipos, tem um tom celebratório - e isso, se não era inédito, era novo pela extensão do projeto e por sua enorme repercussão. 
Já mencionamos antes alguns artistas que precederam Peixoto e Bittencourt nesse movimento. A música foi a área mais importante em que o processo dialógico interclasses e interétnico já evoluíra, bastando lembrar que havia mais de uma década que Chiquinha Gonzaga lançara seu grito de abre alas para o povo da lira. No teatro, Vasques e Xisto Bahia, Artur Azevedo e França Jr., atrizes como Aurélia Delorme, introduzindo o rebolado, também abriram alas e na esteira deles surgiu toda uma geração de revisteiros que pôs nos palcos o maxixe, o cordão carnavalesco e a mulata sestrosa. Um escritor de prestígio nas altas rodas como João do Rio combinava horror e atração pelo baixo mundo da cidade. Em seus escritos, não escondia a enorme distância que separava seu mundo daqueles bárbaros - a quem, como um dândi, observava. Mas se o fosso de classe que os separava era evidente, também o era o desejo de construir pontes.

Todos esses escritores e artistas estavam longe de ser o que Gramsci chamou de intelectuais orgânicos da classe operária. Poucos deles tinham contato mais íntimo com os meios propriamente populares. Não equivaliam a Lima Barreto, exemplo talvez singular naquele momento, cujos escritos, sim, revelam a propalada (pelos críticos de Forrobodó) observação mais próxima e acurada do comportamento de populações pobres e suburbanas, afastando-se do exótico, da paródia, da caricatura e da troça sobre a ignorância. Para isso, já bastava a imprensa "branca", que o fazia em abundância. Lima Barreto tratava os pobres com um respeito em geral ausente no mainstream. Não que fosse um escritor da classe operária, pois num país de analfabetos, seu reduzido público era a mesma elite que, em sua maioria, desprezava a cultura popular e em especial seus traços de origem africana.

Luís Peixoto, Carlos Bittencourt e outros artistas da indústria de entretenimento falavam para um público mais amplo. Faziam parte da mesma elite burguesa consumidora de produtos literários, mas de uma fração dessa elite que reagia contra a postura anticultura popular dos grupos hegemônicos. Tentavam lidar com a questão (crucial para a intelligentsia) da nacionalidade, lançando um olhar mais benigno para o que mais aterrorizava as classes dominantes: $\mathrm{O}$, digamos assim, "pé na África" daquela sociedade. Para tanto, estavam usando um meio de enorme popularidade - o teatro musical ligeiro -, com todos os seus ingredientes principais: humor, sensualidade, música, dança e diversão.

Raul Pederneiras pertencia a esse mesmo grupo. Seu interesse pela linguagem das classes subalternas levou-o a elaborar o já mencionado glossário de gíria Geringonça carioca. No prefácio, datado de maio de 1910, ele apontava para o diálogo interclasses e interétnico que deveria funcionar como matriz da identidade nacional: "A geringonça carioca nasceu do vulgo híbrido, da mestiçagem que formou a nacionalidade. A primeira a destacar-se foi a do capoeira" (Pederneiras, 1920, p. 3, grifo meu).

Ele considerou que o momento dialógico constituidor de uma forma nacional de se falar fora o do contato sistemático entre políticos e capoeiras no século XIX, quando os primeiros contratavam os últimos como capangas para ajudá-los a impor pela violência seus interesses eleitorais. Uma associação íntima estabeleceu-se então, o que deu margem a um intercâmbio lingüístico:

A vida quase em comum dos politiqueiros e demagogos de antanho com os capoeiras estabeleceu uma permuta de vocábulos; lugares comuns, chapas parlamentares, eram adotadas ou adaptadas pelos capadócios, os tropos da retórica dos pais da pátria transferiam-se para o vocabulário dos pernósticos guarda-costas. Assim se explica o gênero rebuscado que floresceu na linguagem dos guaiamus e nagôas, assim se justifica a entrada de termos capadócios no campo do falar comum (Idem, ibidem, grifos do autor).

O estilo rebuscado dos capadócios, já vimos, é uma das fontes principais de sátira em Forrobodó. Como no caso de Peixoto e Bittencourt, Raul Pederneiras, ao estudar a fala dos grupos de baixa escolaridade, sofria de uma ambigüidade. De um lado, procurava valorizar algo que era amplamente depreciado; de outro, não podia se livrar inteiramente de preconceitos fortemente enraizados. Em certo ponto do prefácio, quase chega a pedir desculpas por escrever aquele glossário:

Em todas essas gírias há muito que respigar; na expressão grosseira ou exótica há, de onde em 
onde, tropos felizes e expressivos simbolismos. Estudá-los não é consagrá-los, é pesquisar as causas das linguagens diferenciadas (Idem, p. 4).

Raul Pederneiras, João do Rio, Luís Peixoto e Carlos Bittencourt - todo um grupo de jornalistas, escritores e artistas intrigados com e atraídos por este Outro dentro de sua própria cultura - eram como antropólogos descobrindo selvagens do outro lado da rua em que moravam e procurando entendê-los. Faziam-no, porém, não com a frieza e a distância da ciência, mas com corações apaixonados, e tal envolvimento aparecia em seus textos.

Uma apropriação paródica caracteriza-se por um movimento simultâneo em duas direções opostas. De um lado, parte de um sentimento de inferioridade em face do objeto parodiado - o parodista reconhece que a única forma de replicar o parodiado é por meio de uma cópia empobrecida. De outro, a paródia retira seu objeto das alturas e o traz para a planície, onde perde sua aura e se torna tão pedestre quanto o parodista. E nesse terreno o parodista se sente superior, ao expor todos ao ridículo, inclusive a si mesmo. Sua superioridade consiste justamente na capacidade de rir, ao passo que o parodiado se escuda numa pomposa seriedade.

Quando no final do século XIX o projeto intelectual de criar um teatro nacional "sério" foi derrotado pelo entusiasmo das platéias cariocas com os musicais ligeiros, uma das estratégias de autores e atores para competir com os sofisticados produtos do cancan francês e da opereta austríaca foi a paródia. Curiosamente, aliás, paródia de segundo grau, uma vez que o próprio produto europeu já parodiava burlescamente a cultura clássica. No Brasil, é interessante traçar um paralelo com o processo lingüístico do século XIX, descrito por Raul Pederneiras. Os capoeiras, numa sociedade escravista, estavam numa situação de inferioridade estrutural. Ao imitar a fala dos brancos de classe alta, reafirmavam sua inferioridade, ao mesmo tempo em que adquiriam poder. Não importava que a cópia fosse imperfeita e empobrecida. Num duplo movimento, eles se afirmavam superiores aos seus pares que não dominavam a linguagem dos poderosos, e riam desses últimos em sua pompa e circunstância. Quanto mais o capoeira se esforçasse para imitar a fala de seu patrão, mais intensamente ele expunha o "rei nu".
Quando Peixoto e Bittencourt se apropriaram da linguagem afetada dos capadócios, sua imitação era, por assim dizer, de segundo grau, isto é, a caricatura de uma paródia. Já mencionamos como essa troça em cima do linguajar dos negros era comum nas décadas iniciais do século $\mathrm{XX}$. Mas se tratava, em geral, de uma crítica vazia, que não reconhecia o grau de ridículo anterior. Em Forrobodó, ao menos para um leitor de hoje, o ridículo por trás do ridículo salta imediatamente à vista. É impossível olhar para aquele grupo de pessoas negras e pobres, em roupas formais, transformando situações comuns em solenes, fazendo discursos "pré-fabricados", usando termos grandiloqüentes e expressões estrangeiras, sem rir da "alta sociedade" que eles estavam replicando uma sociedade e um comportamento que uma década adiante se tornariam o alvo da fúria modernista, tachados de "pré-modernos".

Quando no segundo ato, em pleno baile, um "jornalista" adentra o recinto (na verdade um contínuo de jornal), Barradas, o presidente do clube, apela ao orador oficial, Escandanhas, para que profira um discurso em homenagem ao nobre visitante. Escandanhas tira várias folhas de papel da aba do fraque e começa a ler um sermão fúnebre.

Meus senhores, minhas senhoras de ambos os sexos: Revertere ad locum tum! Faltaria ao mais salgado dos deveres, se, neste momento solênico não erguesse minha débil voz para exaltar a colidade orgânica daquele que desapareceu! (Peixoto e Bitterncourt, 1961, p. 8, grifos do autor).

Além de explorar o cômico da situação (trocar um discurso de saudação por um fúnebre), os autores fazem troça da fala de negros pobres com seus erros gramaticais. Mas o estilo e o gosto em si por discursos claramente ridicularizam os hábitos das classes altas. Talvez esse grau de transparência que temos hoje não fosse o mesmo em 1912. Talvez Peixoto e Bittencourt não tivessem consciência da dupla crítica. Mas eles estavam, sem dúvida, em campo oposto aos que apenas desprezavam e temiam a má influência da população e da cultura de origem africana na construção da idéia de uma nação brasileira.

Nossos autores apropriaram-se dessa linguagem paródica e caricaturaram-na para fazer rir, 
mas também para celebrar sua riqueza, seu colorido, sua verve. Da mesma forma, construíram personagens baseados em estereótipos que asseguravam a comicidade, mas que também eram cheios de charme e conquistavam a platéia. A ambivalência é a regra: o Guarda é corrupto, mas por uma boa razão. Roubou as galinhas para trazê-las para a ceia do clube. Ele é ao mesmo tempo agente e infrator da ordem. Depois de terminado seu plantão, transforma-se em mais um membro do povo da lira, trapaceiros que gozam a vida. Barradas, o comerciante português, controla o dinheiro, é burro e violento, mas generoso também, oferecendo casa e comida aos membros do clube.

Quanto ao enredo, a crítica de $A$ Noite estava certa: "Forrobodó é... um forrobodó completo" - no duplo sentido da palavra: desordem e festa, uma "encrenca" no dizer do crítico. Vários incidentes ameaçam o baile: o roubo de galinha, um porteiro que não deixa entrar quem está em débito com o clube, a chegada dos mulatos corretos, que abafam a banca, isto é, concentram a atenção das mulheres, o capoeira encrenqueiro, que quase provoca uma briga de sangue. Mas todos os obstáculos são imediatamente transformados em festa: dançar, cantar, comer, beber, flertar - numa palavra, celebrar.

Este era o espírito do teatro musical ligeiro: a celebração. Que esta se voltasse para um ambiente pobre de subúrbio era uma novidade. Mas isso ainda não é suficiente para explicar o entusiasmo provocado por Forrobodó. Sem dúvida, há de se reconhecer o talento de Peixoto e Bittencourt. Eles escreviam, como disseram os críticos de então, com graça e verve. A peça mantém-se saborosa ainda hoje, apesar da ingenuidade. Em 1995, foi remontada com moderado sucesso. Mas outros elementos foram tão importantes quanto o texto e a música para que o espetáculo se tornasse tal fenômeno.

$\mathrm{Na}$ época da estréia de Forrobodó, a Cia. do Teatro S. José estava por completar um ano com um bem-sucedido projeto de teatro "popular" assim, entre aspas, porque na verdade não se tratava de uma cultura do povo, mas para o povo, ou cultura de massa em termos atuais. A fórmula fora testada em dois espetáculos em que Pascoal Segreto se associara à companhia de Cinira Polônio, atriz experiente e cançonetista de talento. O maxixe (1905) e Dinheiro haja! (1908), ambos de João Foca, o primeiro em parceria com Dom Xiquote (Bastos Tigre) e o segundo com Ataliba Reis, provaram que havia bom público para musicais ligeiros nacionais que investissem numa certa noção de brasilidade, baseada em valores da cultura popular.

A parceria firmou-se com a criação de uma companhia permanente no São José, incorporando outras estratégias testadas com sucesso: três sessões por noite e preços baixos. Cinira e Segreto acreditaram na produção nacional e, antes do primeiro aniversário de sua sociedade, o palco do São José já era considerado o mais importante no Rio de Janeiro para autores brasileiros. Nos demais teatros, eles concorriam em desigualdade de condições com as companhias portuguesas, no gênero de revista, e com as de outras nações européias, nos gêneros mais nobres.

É verdade que Segreto não acreditou no sucesso de Forrobodó e não investiu quase nada na produção, o que torna o êxito ainda mais surpreendente. Cenários e figurinos foram reaproveitados de produções anteriores e, apesar de que ainda não havia chegado o tempo dos shows luxuosos, isso constituía uma falta imperdoável nos musicais. Com toda a experiência que já acumulava no negócio de entretenimento, Segreto não podia acreditar que uma peça toda centrada no povo da lira pudesse estourar. Mas depois do sucesso soube aproveitá-lo bem, e por mais de dez anos o São José foi o templo das revistas e burletas nacionais. O empresário explorou o gênero forrobodó (que ao longo do tempo foi perdendo seu caráter subversivo e se tornando mais "branco") até a exaustão.

O elo que falta analisar para entendermos o sucesso de Forrobodó é o mais difícil de ser reconstituído historicamente: o da performance propriamente dita - o momento mágico e irrecuperável de contato entre atores e público. A atmosfera de emoção que se criou naquele momento ficou marcada apenas nos corpos e nas mentes dos que o viveram e está irremediavelmente morta. O enorme sucesso da peça e a verdadeira lenda em que se transformou atestam o impacto profundo que causou. Pudemos ver como o momento foi preparado para tal impacto. Tudo conspirou para que Peixoto e Bittencourt, Chiquinha, Segreto, Cinira e Alfredo Silva se juntassem e trouxessem para o público o que ele desejava. 
Mas se os elementos estavam lá, foram Cinira Polônio e sua companhia que funcionaram como a fagulha que acendeu a fogueira. Os atores, em geral, encontravam-se numa posição muito melhor para servirem de ponte entre a cultura popular e a erudita do que os dramaturgos. Eram de origem social e étnica mais misturada, ocupavam uma posição mais baixa na hierarquia social, costumavam lutar contra dificuldades econômicas e preconceitos morais, levavam uma vida boêmia e compartilhavam espaços com o povo da lira. Dançavam o maxixe, jogavam capoeira e conviviam com os músicos, entre os quais a mestiçagem cultural já se fizera mais profunda.

Cinira Polônio era uma dama no meio dessa turma de peões. No momento de Forrobodó, tinha 51 anos e vinha de uma longa carreira de sucesso como divette dos musicais ligeiros. Tivera educação privilegiada para a época e estudara canto, dança e atuação na Europa. Falava várias línguas. Atuara em palcos de diversos países. $\mathrm{Na}$ juventude, tentara seguir carreira nos gêneros mais prestigiosos - primeiro ópera, depois opereta -, mas foi como cançonetista que alcançou reconhecimento. Voltou ao Brasil em 1900, produzindo seus próprios trabalhos, e empenhada na criação de um teatro "popular". A parceria com Segreto foi uma conseqüência lógica.

Em Forrobodó, Cinira criou o papel que the cabia como uma luva: a grande dama do baile, a "francesa" Madame Petit-Pois, encarnando um símbolo sofisticado do desejo masculino. Quando Madame Petit-Pois entra no salão, como acompanhante do capoeira Lulu, todos os homens da festa se interessam por ela. É uma rainha, na mesma proporção em que Cinira era a rainha do "teatro popular". Nem ao menos importa que Madame Petit-Pois fosse uma falsa francesa, como aliás as pessoas no baile se dão conta imediatamente. Todos os homens ficam sob seu encantamento, a ponto de Zeferina, a mulata sensual, ter que defender ferozmente seu interesse por Escandanhas, que também se derrete com a "francesa".

\section{ZEFERINA}

$\mathrm{Tu}$ me arrespeita, viu? Olha que eu sou muito home para arrancá os chichis dessa polaca! (Idem, p. 11).
Para as outras mulheres, Petit-Pois não passa de uma vagabunda polaca, prostituta de segunda categoria. Para os homens, é uma divina Madame. $\mathrm{Na}$ realidade, deve ser mesmo brasileira. Mas pouco importa a realidade. Como paródia das verdadeiras rainhas, é trazida para a terra e pode se tornar o objeto de desejo de homens humildes.

Cinira Polônio já era a grande dama do teatro musical ligeiro e era isso que ela representava em cena. Não precisava se demorar no palco. Na verdade, seu personagem só faz uma rápida entrada no terceiro ato. Mas Cinira entrava como estrela, desejada por todos, cantava um dueto com Alfredo Silva no papel de Guarda, dançava um maxixe, sentava no colo de João Matos no papel do capoeira Lulu e saía. Isso foi o suficiente para que todos os críticos a mencionassem como um dos pontos altos do espetáculo.

Cinira Polônio, como sempre, esteve soberba no papel de Mme. Petit-Pois, elegante e chique, emprestando ao personagem a graça parisiense de que é dotada (Gazeta da Tarde, 12/6/1912).

A nossa Cinira pouco tem de fazer... [mas] foi muito bem, o que aliás é dispensável referir, porquanto ela não sabe fazer outra coisa (Diário de Notícias, 12/6/1912).

Mas se a Cinira bastava emprestar ao personagem o brilho de sua majestade falsa, porém cheia de charme, ao restante do elenco cabia tarefa mais ingrata. Estavam longe de reproduzir no palco o que eram na vida real. Tratava-se de uma trupe de atores em geral de classe média, brancos (ou "quase brancos", no feliz dizer de Caetano Veloso), que representavam personagens negros e pobres. Nisso, aliás, pode estar um dos segredos para o sucesso estrondoso e imediato de Forrobodó. Eles tocaram uma corda sensivel dos temores e desejos inconscientes da classe média branca (ou culturalmente branca), ao mesmo tempo em que ofereciam a negros e mulatos um status que não tinham tido antes naquela sociedade. A classe média branca e mestiça carioca estava lidando com os seus fantasmas, por meio desses atores brancos representando papéis de negros. Estava se confrontando com sua posição dúbia entre branco e negro, entre a alta burguesia e o proletariado, entre a fascinação pelo projeto de uma sociedade moderna e europeizada 
e seus vínculos tradicionais com uma realidade afro-lusitana.

O medo da violência negra era um sentimento que tinha acompanhado a população branca desde os tempos coloniais. Em meados do século XIX, o Rio de Janeiro era a maior cidade escravista do mundo ocidental. Viajantes descreviam-na como uma cidade africana. A forte imigração portuguesa na segunda metade do século confirmou esse perfil luso-africano com que entraria no Novecentos. A abolição se fizera há pouco mais de vinte anos e os negros se mantiveram marginalizados, pobres e discriminados.

Parte das elites políticas e intelectuais daquele início de século XX sonhava com a construção de uma França nos trópicos. Para uma população carioca altamente miscigenada e com forte contingente de negros, tal sonho não passava de uma quimera. Atores brancos representando personagens negros de forma bem-humorada e celebratória ofereciam uma solução diferente: as inversões de sinais retiravam o perigo, as diferenças tendiam a desaparecer. Somos todos negros, somos todos brancos, somos todos felizes e gozadores. Podemos desejar a divina francesa ou a sensual mulata, desde que tudo acabe num grande forrobodó. O teatro musical estava lançando as bases para uma nova utopia, a de um país sem classes e sem raças. Negro e branco, rico e pobre, bom e mau -, em vez de afirmar as polaridades, o melhor era embaralhá-las. Em menos de vinte anos, o mito da democracia racial estaria solidamente enraizado.

O sonho no Rio de Janeiro de 1912 era o sonho de um sonho. Sua natureza paródica sempre o referia a um elemento externo. Um talentoso elenco de comediantes brancos estava fazendo uma população miscigenada rir da sua "negritude", rir do seu desejo de ser "branca" e celebrar a ambivalência. Ainda lutando contra a sua dependência de Portugal, o teatro no Rio de Janeiro dirigia finalmente seu olhar para o temido (e surpreendentemente desejado) Outro da cultura. A burleta do povo da lira é a perfeita paródia das operetas que descrevem as delícias das folias parisienses; paródia não como gênero, mas como uma ampla estratégia cultural inconsciente. A cidade também se movia ao ritmo de Franz Lehar, mas Chiquinha Gonzaga fazia o contraponto. Os come- diantes brancos fazendo troça do bairro negro da Cidade Nova, com seus capoeiras e capadócios, esvaziavam-no de seus aspectos perigosos e o preenchiam com alegria de viver e espírito folião. Outro poderoso mito estava em processo de construção: o de uma população pobre, porém feliz.

O herói dessa história faz finalmente sua entrada em cena: Alfredo Silva. Em Forrobodó, no papel de Guarda, era ele quem comandava a festa e confirmou sua posição na cidade como "o Rei do Riso" (Gazeta da Tarde, 12/6/1912) - posição nobre, que o situava à altura de sua companheira de palco, Lady Polônio. Mas ao contrário dela, seu personagem não tinha nenhuma majestade: era um guarda noturno, um pobre mulato que falava errado e enfrentava as agruras da vida com uma ética dúbia. Mas Alfredo Silva reinava no palco e criou um Guarda que ficou na memória dos freqüentadores de teatro por um longo tempo. Um dos momentos principais da peça é quando Madame Petit-Pois e o Guarda cantam em dueto e dançam um maxixe.

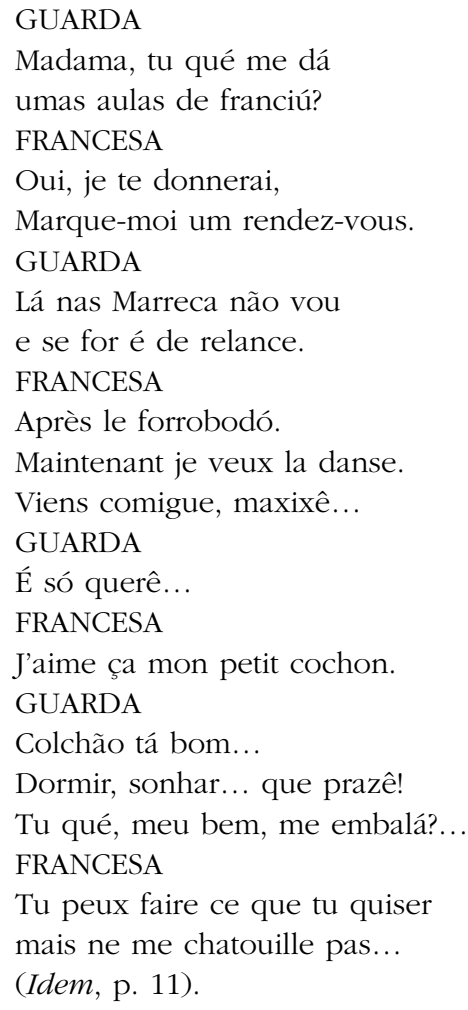

A cena, com seus duplos sentidos e a ambigüidade de seus personagens, era o momento, à 
altura da metade do espetáculo, em que todos paravam para homenagear o falso casal real. Como Cinira, Alfredo Silva era um ator respeitado na época da estréia de Forrobodó. Embora bem mais novo, vinha atuando profissionalmente por ao menos 20 anos. Era um homem grande, com aparência senhorial. No início da carreira, atuara como ator dramático, para o que teve seu talento reconhecido. Em 1907, foi o personagem principal de O dote, de Artur Azevedo, num último esforço deste de abrir espaço para uma dramaturgia nacional "séria".

Talvez tenha sido a própria limitação do mercado para esse tipo de produto que teria levado Alfredo Silva para os musicais ligeiros, nos quais firmou sua reputação como comediante. Seu talento cômico, como para a dança e para o canto, logo o tornaria uma estrela no universo dos musicais, com reconhecimento tanto de platéias mais exigentes, como do público das "torrinhas" (galerias). Alguns anos depois da estréia de Forrobodó, porém, o ator passou a sofrer ataques recorrentes na imprensa, de críticos mais conservadores, por consagrar um estilo de atuação beirando o vulgar, como demonstra um comentário anônimo de 1917, que acusava o ator de inventar o estilo "meleca":

[...] o público tem de gramar o "gênero [forrobodó]", muita vez mesmo torcendo o nariz ao "gênero" [...], verdadeiramente enojado das palhaçadas, gaiatadas e "melecas" com que o ator Alfredo Silva entende de colaborar nos trabalhos alheios. Essa da "meleca" é colaboração dele no antigo "Forrobodó". Criou estilo, fez carreira. É esse o "espírito" com que ele delicia os freqüentadores do teatro (Comédia, 3/2/1917).

O fato é que Alfredo Silva passou a arrastar multidões ao teatro, sendo por muitos anos o esteio do São José. A dignidade e o porte senhorial que lhe eram reconhecidos no gênero dramático seguramente contribuíram para a majestade pedestre do Rei do Riso nos gêneros "populares". Comandando um elenco de atores brancos que representavam personagens negros, esse rei carnavalizado contribuiu com seu prestígio para dar reconhecimento público para um assunto que até então era motivo apenas de desprezo. É impossível recuperar o efeito carismático de sua presença em cena, mas pelo que ficou de testemunho, podemos extrair uma impressão geral de facilidade e graça no atuar: "a graça sempre natural de Alfredo Silva" (Folha do Dia, 12/6./1912); "o sr. Alfredo Silva, como sempre, à vontade" (Jornal do Brasil, 13/6/1912); "Alfredo Silva, com aquela graça que todos the reconhecem" (Diário de Notícias, 12/6/1912).

O tipo do Guarda criado por Alfredo Silva tem antecedentes no teatro carioca, mas firmou uma concepção marcada pela dubiedade, mais do que pela crítica pura, que teria vida longa no teatro de revista. Combinando sua autoridade e carisma com o caráter corrupto, mas folião e simpático do agente da lei, o personagem tornou-se emblemático da ambivalência entre ordem e desordem, o que passou a ser recorrente na produção artística moderna brasileira. Antonio Candido já apontava para isso nas Memórias de um sargento de milicias, com a "dança de personagens entre o lícito e o ilícito" (Candido, 1970, p. 82). Ressalta, no entanto, a posição isolada de Manuel Antônio de Almeida naqueles meados do século XIX, com o seu estilo coloquial e a abertura para os ritmos do povo (Idem, p. 87) e chama as Memórias de romance malandro (Idem, p. 71). Manuel Antônio de Almeida estaria mais próximo das comédias de costumes de Martins Pena do que da literatura produzida em sua época. Sessenta anos depois, Forrobodó, através da performance rasgada de Alfredo Silva no papel de Guarda, estava retomando este quase perdido jogo da ambivalência popular diante da ordem, com um tom farsesco. Que o tipo caísse nas graças das platéias por longos anos aponta para uma identificação destas com o antiherói, mais capaz de falar de uma desejada "brasilidade" do que os nobres esforços da produção artística "séria".

O Guarda, em Forrobodó, é um trapaceiro. Capaz de pequenos crimes, como o roubo das galinhas, faz parte do povo da lira e se junta aos companheiros de farra assim que termina seu turno. Fala a linguagem dos capadócios, flerta com a mulata Zeferina e com a francesa Petit-Pois, toca clarineta e acordeão, dança o maxixe e come com apetite pantagruélico. Covarde, quando o capoeira Lulu o chama para briga, esconde-se debaixo da mesa até que termine o turumbamba.

Alfredo Silva, sem perder o espírito de comédia, poderia ter realçado o lado negativo na tradi- 
ção de guardas que vinha do próprio teatro de revista português, como tipos atrabiliários e corruptos, transformando sua performance numa crítica à polícia. Ao contrário, tirou plena vantagem das ambigüidades já presentes no texto para fazer do seu Guarda o rei do povo da lira. Como representante da lei e do Estado na Sociedade Flor do Castigo do Corpo da Cidade Nova, deu ao personagem a grandiosidade paródica da sua posição. A impressão que deixou nas platéias foi menos de um misto de autoridade e contraventor contumaz e mais do malandro criativo e folgazão, capaz de extrair da vida as oportunidades de gozo que lhe oferecia. Nas palavras do Diário de Notícias $(12 / 6 / 1912)$, estava "mais preocupado com as doçuras do maxixe do que com os afazeres do cargo, tendo a respeito de polícia as mais adiantadas idéias".

A atitude de resistir à violência institucional e às agruras da vida com esperteza e espírito festeiro nascera e se desenvolvera nas classes populares, dando vida a tipos e personagens como o Zé Pelintra, o capoeira, o capadócio, o malandro, o povo da lira. Agora era a classe média carioca que ansiava por adotar tal atitude na representação de sua identidade - um meio de sublimar as dificuldades da vida: pobre, porém feliz. Se os "brasileiros" não podiam ser tão poderosos e sofisticados como os "europeus", se não podiam usufruir os frutos do capitalismo avançado representados nas operetas francesas e austríacas, ao menos a esperteza os ajudava a enfrentar tudo com alegria e festa. Não tinham o cancan, mas tinham o maxixe. O Guarda de Alfrerdo Silva sintetizava todos esses sentimentos.

Ambivalência e ambigüidade eram as regras do jogo. Vimos como Peixoto e Bittencourt lidaram com a ambigüidade na linguagem. Uma fala recorrente do Guarda é "Não se impressione". Os autores usaram o artifício da repetição, conhecido mecanismo de comicidade. Alfredo Silva tirou tanto proveito disso, que a frase se tornou um sucesso e entrou no vocabulário da cidade. O interessante, mecanismo aliás também recorrente nas gírias, é como a frase é deslocada para não dizer o que realmente significa e só se ressignificar em contextos específicos. Conforme o momento, pode querer dizer "não se preocupe", "fique à vontade", "me dá um tempo" etc. O efeito de disjunção entre palavras e significados, que em si traz comicidade, reforça o jogo de aparência e realidade da peça, em que nada é exatamente o que parece. Alfredo Silva era um homem branco, de classe média e alta escolaridade, que representava um mulato pobre e ignorante; o Guarda, um agente da ordem, mas também um ladrão de galinhas; personagem objetivamente mau, mas bom no coração da platéia; dizia uma coisa, mas significava outra.

Assim, quando Coelho Neto dizia que o Brasil não tinha uma dança própria porque não tinha uma raça própria, estava expressando a preocupação de certas elites de que o problema da cultura brasileira era a indeterminação. A resposta da intelligentsia carnavalesca foi que a indeterminação não era o problema, mas a solução. Era a ambigüidade que permitia o sonho com uma sociedade sem classes e sem raças. Eram a ambigüidade e a ambivalência que permitiam lidar com as complicadas relações entre negros e brancos, Europa e África, ricos e pobres, ordem e desordem, os valores do Ocidente capitalista cristão e o seu assustador, mas atraente Outro.

A frase "não se impressione" pode ser vista como uma espécie de slogan das relações ambíguas. Dito por Alfredo Silva no palco, com seu carisma e talento cômico, passou a encarnar uma certa imagem do "carioca" que as platéias assimilaram de bom grado. Para tanto, Chiquinha Gonzaga também deu sua contribuição. Sua principal composição para a peça - conhecida como Forrobodó de massadas - abre com esse dito. A canção foi cantarolada pela cidade, lado a lado com o transeunte que assoviava o tema de $A$ viúva alegre, sonhando com o luxo e charme das cidades européias.

Secundando Alfredo Silva, aparecia Asdrúbal Miranda no papel de Escandanhas da Purificação, o afetado secretário da sociedade dançante. O nome do personagem já é em si uma piada. Escandanhas remete tanto para "escandir" (decompor [um verso], destacar as sílabas na pronúncia [de um verso, de uma palavra]), quanto a "escandescer" (inflamar[-se], excitar[-se]). O último sentido, associado à "purificação", traz conotações ainda mais engraçadas, além de alusões que podem ser vistas como racistas. Piadas de mau gosto com a cor preta e seus contrastes coma as idéias de pureza, luz, limpeza etc. eram comuns na im- 
prensa da época, muitas vezes voltadas contra figuras públicas, como o já mencionado deputado Monteiro Lopes ou o gramático Hemetério. O nome completo, Escandanhas da Purificação, tinha ainda uma cômica ressonância, a qual remetia a certo hábito de nomes extravagantes nas comunidades negras.

Ainda mais do que o personagem do Guarda, o fato de Escandanhas ser representado por um ator branco (ou "quase branco"1) causava certo efeito de estranhamento, digamos assim, brechtiano avant la lettre, pois o personagem do negro afetado era amplamente caricaturado e presente no imaginário popular. Ainda nesse caso, a novidade era o enfoque positivo dado por Peixoto e Bittencourt. Escandanhas é um poeta, e como tal, um príncipe. Como sempre, prevalece o modo paródico. Ele fala usando palavras rebuscadas (e incorretas), usa metáforas, cita autores clássicos (incorretamente), numa paródia da intelectualidade pomposa brasileira. Já em sua primeira intervenção, é comparado pelo Guarda a Homero e Rui Barbosa. Mais adiante, Escandanhas atribui um dito popular ("saco vazio não fica em pé") ao "grande fisólofo lusitano Jaques Pires" (Peixoto e Bittencourt, 1961, p. 9).

As referências que encontrei para avaliar as performances dos outros atores são ainda mais econômicas em seus comentários. Afora alguns elogios genéricos, o que podemos extrair é que a performance de Asdrúbal Miranda foi "inteligente" - que era justamente a qualidade necessária para o jogo de louvação e escárnio num personagem que parodiava a inteligência. Não é difícil supor que atores como ele, filho de imigrantes pobres, mais próximo do povo da lira, transmitissem vida e simpatia na construção de uma caricatura marcada pelos preconceitos em voga. É possível presumir-se com certa segurança que, por meio da performance, a paródia da retórica pomposa e vazia e a crítica ao falar incorreto viessem acompanhadas da alegria de viver, da sensualidade e da celebração que emanam da peça em geral.

Com as atrizes Pepa Delgado, Cecília Porto e Laura Godinho, que fizeram os personagens das mulatas dengosas, o contraste negro/branco também deve ter causado forte impacto. Já havia tempo que a música popular, o carnaval e o teatro de revista vinham celebrando a mulata como símbolo de brasilidade e de sensualidade. Era um terreno em que a ambivalência estava menos presente. Os campos dividiam-se entre entusiastas e inimigos ferozes da mulata como símbolo. Mesmo entre os defensores, "a mulata" não passava de um corpo, a encarnação do desejo de homens brancos, dentro de uma lógica perversa de "mulher branca para casar, mulata para fornicar, negra para trabalhar". Mas também era o símbolo etnicamente ambíguo, nem negro nem branco, que expressava o longamente reprimido desejo do homem branco pela mulher negra - no corpo da mulata, os traços mais agressivos da negritude apareciam suavizados: lábios, nariz, cadeiras, cabelo, cor de pele.

No palco, o que a platéia viu foram atrizes brancas (e desejáveis), adotando gestos como o remexer das cadeiras, comportando-se e falando como o estereótipo da mulata dengosa. A repercussão foi intensa. As críticas destacaram a vivacidade de Pepa Delgado, a sedução de Laura Godinho e a malícia de Cecília Porto (que fazia a mulata Zeferina). Também elas eram dignas princesas da corte de Cinira e Alfredo. Não importava que não fossem mulatas de fato, pois eram igualmente desejáveis.

$\mathrm{Na}$ verdade, o público estava acostumado a ver atrizes francesas, italianas, espanholas e mesmo gregas fazendo papel de mulata. Os musicais eram espetáculos que demandavam a cumplicidade da platéia, e não o teatro da ilusão, da quarta parede. O elenco feminino de Forrobodó não só era branco, mas também relativamente velho. As três mulatas casadoiras eram representadas por mulheres na faixa dos 30 anos. Cerca de metade do elenco era de portugueses, incluindo o capoeira Matos, o afetado capadócio Miranda e a desejável mulata Godinho. Mas no caso específico das mulatas, algo estava começando a mudar. No início da longa carreira de Forrobodó, as primeiras atrizes assumidamente mestiças davam seus passos iniciais nos palcos profissionais Otília Amorim, Júlia Martins e, mais tarde, Araci Cortes se tornariam importantes vedetes do teatro de revista nas décadas subseqüentes.

O personagem da mulher do português lança alguma luz sobre as atitudes prevalecentes em relação aos negros. Rosa não é parte das jovens e belas mulatas, nem tem no texto traços 
de sensualidade. Trata-se da cozinheira ignorante e de aparência ridícula, que praticamente grunhe umas poucas palavras em suas raras entradas. Ela é a única que não é caracterizada como mulata e sim como crioula. É impossível resgatar como terá sido representada, pois não mereceu nenhuma referência nas críticas. É até difícil identificar quem foi a atriz, provavelmente Luísa Lopes. Mas, da forma como o personagem é descrito no texto, desaparece qualquer intenção celebratória, e ficamos apenas com a derrisão.

A mudança de atitude entre mulata e crioula segue um vocabulário preciso: o termo mulato/mulata era, nesse contexto, associado com algum charme e atrativo. Alguns dias antes da estréia de Forrobodó, o jornal O País anunciou o evento com uma imagem sedutora: "Veremos na cena os mulatos sestrosos e as mulatas dengosas nos seu requebros e palavreado especial" $(3 / 6 / 1912)$.

Transformar a mulata num ícone foi talvez o primeiro movimento que brancos cariocas fizeram no sentido de romper seus impasses diante do medo e do desejo firmemente enraizados pelo seu Outro, o negro carioca. No teatro, a mulata sestrosa começou a aparecer nos palcos em fins do século XIX. A contínua moldagem do ícone indicava, de um lado, o progresso em face das atitudes mais abertamente racistas, mas, de outro, carregava todas as complicações da difícil relação interétnica. No plano simbólico, ajudaria a construir o mito da democracia racial. Mas este era um plano seguro, confinado às pranchas do palco. $\mathrm{Na}$ vida real, nada mudaria nas condições extremamente adversas em que a população negra carioca e brasileira vivia.

\section{Notas}

1 Asdrúbal Miranda era açoriano, vindo ainda pequeno para o Brasil. Suas fotos, como acontece com freqüência, não permitem uma avaliação mais precisa de sua origem étnica, até porque, numa sociedade fortemente racista, era desejável (e seguramente praticado) trabalhar a fotografia no sentido de tornar as pessoas com uma aparência mais "branca".

\section{BIBLIOGRAFIA}

CANDIDO, Antonio. (1970), "Dialética da malandragem". Revista do Instituto de Estudos Brasileiros, 8: 67-89, São Paulo, IEB/USP.

GRAMSCI, Antonio. (1985), Selections from cultural writings. Editado por David Forgacs e Geoffrey Nowell-Smith. Cambridge, Harvard University.

GREEN, Abel \& LAURIE Jr., Joe. (1985), Showbiz from vaude to video. Nova York, Garland.

LIRA, Marisa. (1978), Chiquinha Gonzaga: grande compositora popular brasileira. Rio de Janeiro, Funarte.

PEDERNEIRAS, Raul. (1920), Geringonça carioca. Rio de Janeiro, Jornal do Brasil.

PEIXOTO, Luís \& BITTENCOURT, Carlos. (1961), "Forrobodó". Revista de Teatro-SBAT, 323.

RENAUlT, Delso. (1980), "O Rio de Janeiro e suas diversões na época dourada”. L. S. Costa (ed.), Brasil 1900-1910, Rio de Janeiro, Biblioteca Nacional, vol. 3.

TINHORÃO, José Ramos. (1978), Pequena bistória da música popular. 3 ed. Petrópolis, Vozes. 


\section{UM FORROBODÓ DA RAÇA E DA CULTURA}

Antonio Herculano Lopes

Palavras-chave: Teatro; Rio de Janeiro; Cultura afro-brasileira; Mestiçagem; Performance.

A comédia musical Forrobodó, de Luiz Peixoto e Carlos Bittencourt, estreada em 1912 no Rio de Janeiro, abriu caminho para a ampliação do interesse das classes médias cariocas pela cultura produzida no que se convencionou chamar de "Pequena África”. A região em torno da praça Onze tinha uma alta concentração de lideranças espirituais e culturais dos afrobrasileiros e se transformara num viveiro de manifestações que teriam enorme influência na cidade e no país. Minha análise se concentra menos no texto e mais na performance em si, no sentido de apreender como os mitos de uma identidade mestiça começam a se construir. Todos os elementos da produção da peça se combinam para preencher a necessidade de grupos da classe média branca carioca de uma representação ambígua e ambivalente de raça e classe na cultura da cidade.

\section{A CONFUSION OF RACE AND CULTURE}

Antonio Herculano Lopes

Keywords: Theater; Rio de Janeiro; Afro-brazilian culture; Mestizing; Performance.

The musical comedy Forrobodó from Luiz Peixoto and Carlos Bittencourt first performed in 1912 in Rio de Janeiro opened way to broadening the interest of Carioca middle classes in the culture produced in what was then qualified as "Little Africa." The region around Onze Square concentrated most of the spiritual and cultural leadership of Afro-Brazilians and had become a coop of manifestations that would have an enormous influence on the city and the country. This analysis focuses less on the text and more on the performance by itself, aiming at learning how the myths of a mestiza identity started to comprise. All the elements of the production of the play mingle to fill the necessity of Carioca middle class groups for an ambiguous and ambivalent representation of race and class in the culture of the city.

\section{UNE PAGAILLE DE RACE ET DE CULTURE}

Antonio Herculano Lopes

Mots-clés: Théâtre; Rio de Janeiro; Culture afro-brésilienne; Métissage; Performance.

La comédie musicale Forrobodó (Pagaille), de Luiz Peixoto et Carlos Bittencourt, dont la première a eu lieu en 1912 à Rio de Janeiro, a ouvert les portes à un élargissement de l'intérêt des classes moyennes cariocas pour la culture produite dans ce qui a été appelé "La Petite Afrique ". La région aux alentours de la place Onze possédait une importante concentration de leaders spirituels et culturels des afrobrésiliens et s'était transformée en une pépinière de manifestations qui auraient une énorme influence sur la ville et le pays. Mon analyse se concentre moins sur le texte et plus sur la performance en soi, dans le sens de comprendre de quelle façon les mythes d'une identité métissée ont commencé à se construire. Tous les éléments de la production de la pièce de théâtre se combinent pour combler le besoin de groupes de la classe moyenne blanche carioca pour une représentation ambiguë et ambivalente de race et de classe dans la culture de la ville. 